\title{
Structure and Physical Properties of PZT-PMnN-PSN Ceramics Near the Morphological Phase Boundary
}

\author{
Nguyen Dinh Tung Luan, ${ }^{1}$ Le Dai Vuong, ${ }^{1,2}$ Truong Van Chuong, \\ and Nguyen Truong Tho ${ }^{2}$
}

${ }^{1}$ The Fundamental Science Department, Hue Industry College, Hue City, Vietnam

${ }^{2}$ Department of Physics, College of Sciences, Hue University, Hue City, Vietnam

Correspondence should be addressed to Nguyen Dinh Tung Luan; ntungluan@yahoo.com

Received 1 August 2013; Accepted 11 December 2013; Published 20 January 2014

Academic Editor: Mohammad Mahroof-Tahir

Copyright (C) 2014 Nguyen Dinh Tung Luan et al. This is an open access article distributed under the Creative Commons Attribution License, which permits unrestricted use, distribution, and reproduction in any medium, provided the original work is properly cited.

\begin{abstract}
The $0.9 \mathrm{~Pb}\left(\mathrm{Zr}_{x} \mathrm{Ti}_{1-x}\right) \mathrm{O}_{3}-0.07 \mathrm{~Pb}\left(\mathrm{Mn}_{1 / 3} \mathrm{Nb}_{2 / 3}\right) \mathrm{O}_{3}-0.03 \mathrm{~Pb}\left(\mathrm{Sb}_{1 / 2} \mathrm{Nb}_{1 / 2}\right) \mathrm{O}_{3}$ (PZT-PMnN-PSN) ceramics were prepared by columbite method. The phase structure of the ceramic samples was analyzed. Results show that the pure perovskite phase is in all ceramics specimens. The effect of the $\mathrm{Zr} / \mathrm{Ti}$ ratio on the region of morphotropic phase boundary for PZT-PMnN-PSN ceramics was studied. Experimental results show that the phase structure of ceramics changes from tetragonal to rhombohedral with the increase of the content of $\mathrm{Zr} / \mathrm{Ti}$ ratio in the system. The composition of PZT-PMnN-PSN ceramics near the morphotropic phase boundary obtained is the ratio of $\mathrm{Zr} / \mathrm{Ti}: 49 / 51$. At this ratio, the ceramic has the optimal electromechanical properties: the $k_{p}=0.61$, the $\varepsilon_{\max }=29520$, the $d_{31}=-236 \mathrm{pC} / \mathrm{N}$, the $Q_{m}=2400$, high remanent polarization $\left(P_{r}=49.2 \mu \mathrm{C} \cdot \mathrm{cm}^{-2}\right)$, and low coercive field $E_{c}=10.28 \mathrm{kV} \cdot \mathrm{cm}^{-1}$.
\end{abstract}

\section{Introduction}

Lead zirconate titanate (PZT) is one of the most commonly used ferroelectric ceramic materials. The material has been studied intensively since discovery of the miscibility of lead titanate and lead zirconate in the 1950s [1-5]. Due to their excellent dielectric, pyroelectric, piezoelectric, and electrooptic properties, they have a variety of applications in high energy capacitors, nonvolatile memories (FRAM), ultrasonic sensors, infrared detectors, electrooptic devices, and step-down multilayer piezoelectric transformers for ACDC converter applications $[5,6]$. Until now, many ternary and quaternary systems, such as $\mathrm{Pb}\left(\mathrm{Ni}_{1 / 3} \mathrm{Nb}_{2 / 3}\right) \mathrm{O}_{3}$ - $\mathrm{PZT}$, $\mathrm{Pb}\left(\mathrm{Y}_{2 / 3} \mathrm{~W}_{1 / 3}\right) \mathrm{O}_{3}$ - $\mathrm{PZT}, \quad \mathrm{Pb}\left(\mathrm{Mn}_{1 / 3} \mathrm{Sb}_{2 / 3}\right) \mathrm{O}_{3}-\mathrm{PZT}, \quad \mathrm{Pb}\left(\mathrm{Mg}_{1 / 3}\right.$ $\left.\mathrm{Nb}_{2 / 3}\right) \mathrm{O}_{3}-\mathrm{Pb}\left(\mathrm{Ni}_{1 / 3} \mathrm{Nb}_{2 / 3}\right) \mathrm{O}_{3}-\mathrm{PZT}, \mathrm{Pb}\left(\mathrm{Ni}_{1 / 2} \mathrm{~W}_{1 / 2}\right) \mathrm{O}_{3}-\mathrm{Pb}\left(\mathrm{Mn}_{1 / 3}\right.$ $\left.\mathrm{Nb}_{2 / 3}\right) \mathrm{O}_{3}$-PZT, and PZT-PMnSbN, $[4,5,7-11]$ have been synthesized by modifications or substitutions to satisfy the requirements of practical applications of piezoelectric transformer.

In ceramics manufacturing technology, piezoelectric PZT system ceramics compositions are mostly near the tetragonalrhombohedral (T-R) morphotropic phase boundary (MPB). The electromechanical response of these ceramics is known to be most pronounced at the MPB. So, there have been many investigations on the coexistence of two phases near MPB in PZT system [3]. The reports suggested the existence of a range of compositions where both tetragonal and rhombohedral phases are thermodynamically stable $[7,12]$.

In this study, $0.9 \mathrm{~Pb}\left(\mathrm{Zr}_{x} \mathrm{Ti}_{1-x}\right) \mathrm{O}_{3}-0.07 \mathrm{~Pb}\left(\mathrm{Mn}_{1 / 3} \mathrm{Nb}_{2 / 3}\right)$ $\mathrm{O}_{3}-0.03 \mathrm{~Pb}\left(\mathrm{Sb}_{1 / 2} \mathrm{Nb}_{1 / 2}\right) \mathrm{O}_{3}(\mathrm{PZT}-\mathrm{PMnN}-\mathrm{PSN})$ ceramics in the vicinity of MPB were investigated according to the $\mathrm{Zr} / \mathrm{Ti}$ ratio content. The purpose of this work is to study structure and ferroelectric and piezoelectric properties in the vicinity of the MPB in detail. Furthermore, the width of coexistence of 


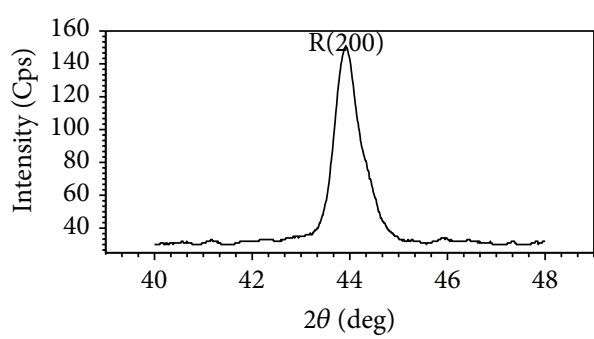

(a)

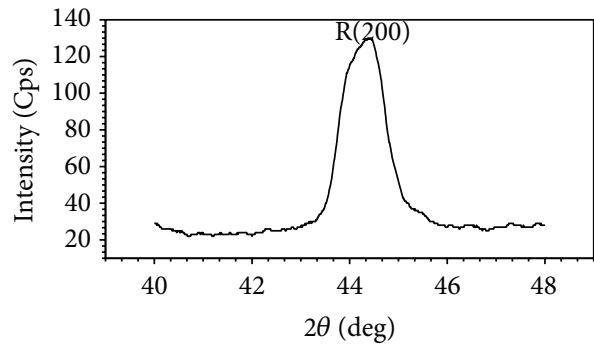

(c)

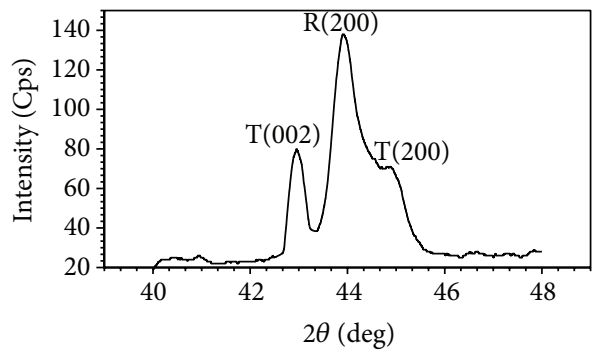

(e)

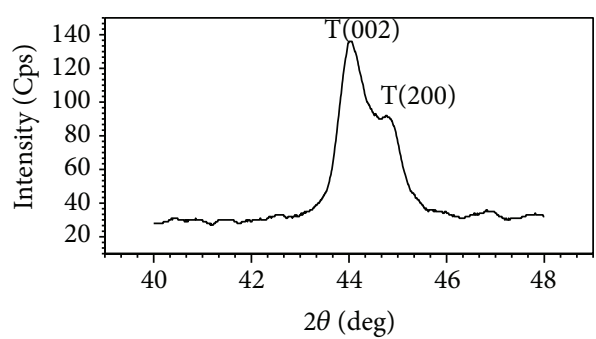

(g)

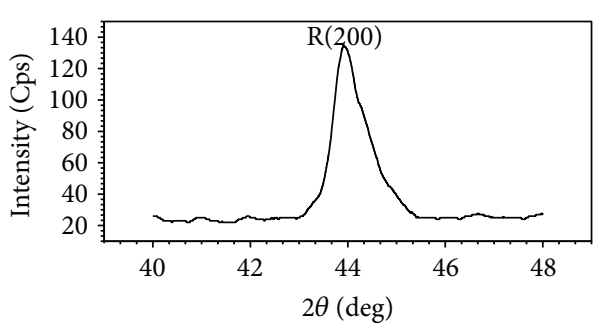

(b)

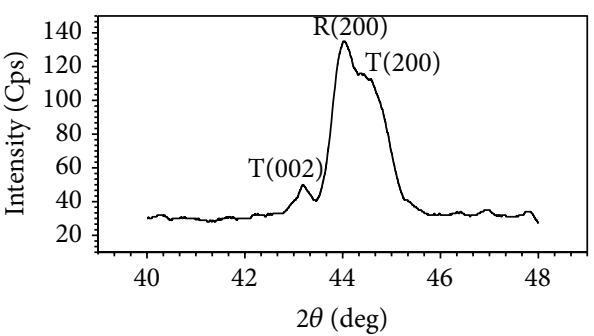

(d)

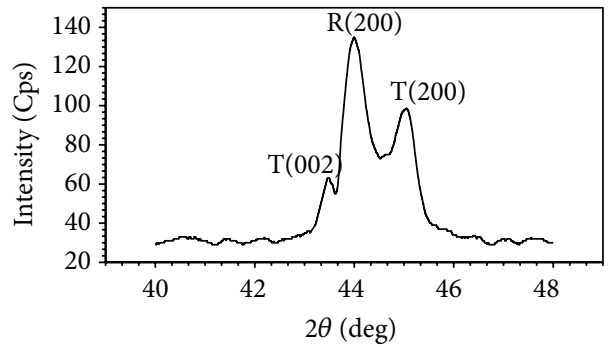

(f)

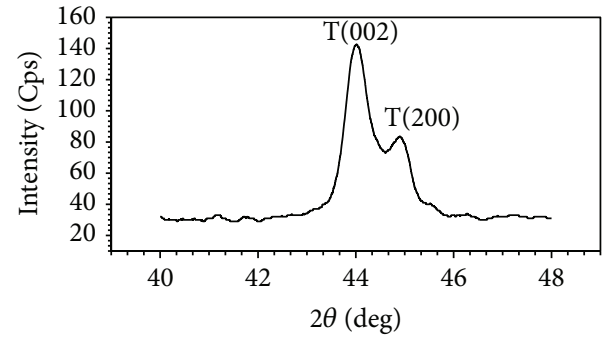

(h)

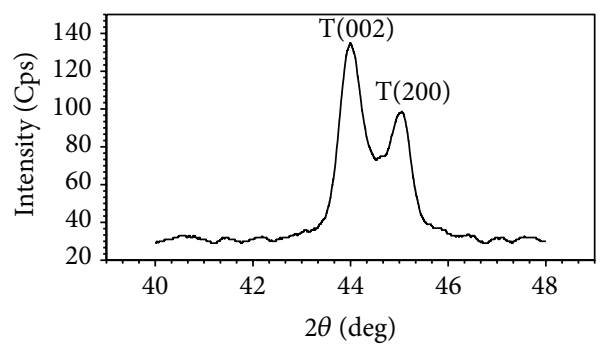

(i)

FIGURE 1: XRD patterns for compositions at (a) 54/46; (b) 53/47; (c) 52/48; (d) 51/49; (e) 50/50; (f) 49/51; (g) 48/52; (h) 47/53; (i) 46/54. 


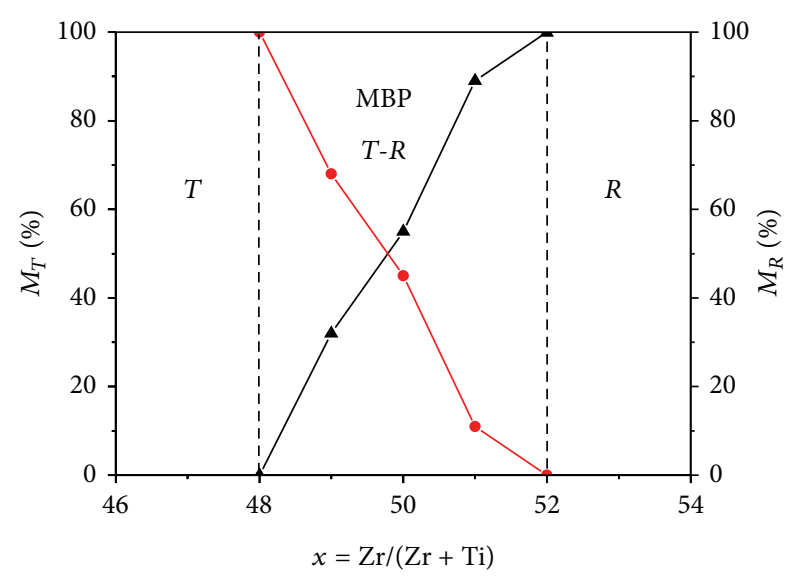

Figure 2: Variations of relative content of the tetragonal and rhombohedra phases with $\mathrm{Zr} / \mathrm{Ti}$ ratio.

tetragonal and rhombohedra phases and the exact composition of the MPB in chemically homogeneous PZT-PMnNPSN ceramics were determined.

\section{Experimentals}

The polycrystalline samples of PZT-PMnN-PSN were synthesized by columbite precursor method. The raw materials including powders (high purity) of $\mathrm{PbO}(99 \%), \mathrm{ZrO}_{2}$ (99.9\%), $\mathrm{TiO}_{2}$ (99\%), $\mathrm{MnCO}_{3}$ (99\%), $\mathrm{Sb}_{2} \mathrm{O}_{3}(99 \%)$, and $\mathrm{Nb}_{2} \mathrm{O}_{5}$ (99.9\%) for the given composition were weighted by mole ratio. First, the finely mixed powder of $\mathrm{MnCO}_{3}$ and $\mathrm{Nb}_{2} \mathrm{O}_{5}$; $\mathrm{Sb}_{2} \mathrm{O}_{3}$ and $\mathrm{Nb}_{2} \mathrm{O}_{5}$ are mixed in a Teflon-mortar for about $10 \mathrm{~h}$ in an acetone medium and then calcined at $1200^{\circ} \mathrm{C}$ in an alumina crucible for $3 \mathrm{~h}$. The calcined powder was then grinded and mixed by mortar again with $\mathrm{PbO}, \mathrm{ZrO}_{2}$ and $\mathrm{TiO}_{2}$ for $30 \mathrm{~h}$. The finely mixed powder was calcined at $850^{\circ} \mathrm{C}$ for $2 \mathrm{~h}$.

The ground materials were pressed into disk $12 \mathrm{~mm}$ in diameter and $1.5 \mathrm{~mm}$ in thickness under $100 \mathrm{MPa}$. The samples were sintered in a sealed alumina crucible with $\mathrm{PbZrO}_{3}$ coated powder at temperature $1150^{\circ} \mathrm{C}$ for $2 \mathrm{~h}$. Scanning electron micrograph of the sample was taken at room temperature. The sintered pellet was polished and silver electroded and connected to an LCR meter (Hioki, Japan) for dielectric measurement. The frequency dependence of dielectric constant and loss tangent were obtained using the LCR meter in the frequency range from $0.1 \mathrm{kHz}$ to $500 \mathrm{kHz}$. The polarization-electric field $(P-E)$ hysteresis loops were measured by a Sawyer-Tower circuit at $50 \mathrm{~Hz}$.

As-sintered samples were ground and polished to remove the surface layer for X-ray diffraction (XRD, D/MAX-RB, Rigaku, Japan). $\mathrm{Cu} \mathrm{K} \alpha$ radiation with a step of $0.01 \mathrm{~s}$ was used. The microstructure of the samples was examined by using a scanning electron microscope (SEM). The electromechanical coupling factor $\left(k_{p}\right)$, mechanical quality factor $\left(Q_{m}\right)$, and piezoelectric coefficient $\left(d_{31}\right)$ were calculated by using the resonance-antiresonance method. The dielectric constant was calculated from the capacitance and the dimension of the samples.

\section{Results and Discussion}

3.1. Structure and Microstructure. It is reported that tetragonal, rhombohedra, and T-R phases were identified by an analysis of the peaks (002 (tetragonal), 200 (tetragonal), and 200 (rhombohedra)) in the $2 \theta$ range $43^{\circ}-47^{\circ}$. The splitting of (002) and (200) peaks indicates that they are the ferroelectric tetragonal phase (FT), while the single (200) peak shows the ferroelectric rhombohedra phase (FR) $[1,6,13]$. Figure 1 shows the XRD patterns of PZT-PMnN-PSN with Zr/Ti ratio at $54 / 46$ up to $46 / 54$. Triplet peaks indicate that the samples consist of a mixture of tetragonal and rhombohedra phases.

A transition from tetragonal phase to rhombohedra phase is observed as $\mathrm{Zr} / \mathrm{Ti}$ ratio increases. The multiple peak separation method was used to estimate the relative fraction of coexisting phases. The relative phase fraction was then calculated by the following equations [14]:

$$
\begin{gathered}
M_{R}=\frac{I_{R(200)}}{I_{R(200)}+I_{T(002)}+I_{T(200)}}, \\
M_{R}=\frac{I_{T(002)}+I_{T(200)}}{I_{R(200)}+I_{T(002)}+I_{T(200)}} .
\end{gathered}
$$

With increasing $\mathrm{Zr} / \mathrm{Ti}$ ratio, tetragonal relative fraction decreases and rhombohedra relative fraction increases. The analysis of the relative phase fraction in the PZT-PMnN-PSN system indicates that tetragonal and rhombohedra phases coexist in the composition range for $0.48 \leq x \leq 0.52$ as shown in Figure 2.

Figure 3 shows the SEM image of the fractured surface of PZT-PMnN-PSN ceramics at different $\mathrm{Zr} / \mathrm{Ti}$ ratios. It is observed from the micrographs that the average grain size of samples are increased with the increasing amount of $\mathrm{Zr} / \mathrm{Ti}$ ratio. However, when further increasing the $\mathrm{Zr} / \mathrm{Ti}$ ratio to $51 / 49$, the average grain size is reduced. These results are in good agreement with the reported in the literature [15].

\subsection{Dielectric and Ferroelectric Properties}

3.2.1. The Influence of Zr/Ti Ratio on the Dielectric Properties. Figure 4 shows the temperature dependence of dielectric permittivity and dielectric loss $\tan \delta$ of PZT-PMnN-PSN system $(1 \mathrm{kHz})$ with $\mathrm{Zr} / \mathrm{Ti}$ ratios $46 / 54$ up to $54 / 46$, respectively. As shown in Figure 4, all the samples in morphotropic phase boundary region $(\mathrm{Zr} / \mathrm{Ti}=48 / 52-52 / 48)$ exhibit typical relaxor ferroelectric behavior around. The dielectric responses are characterized by diffuse dielectric peaks and a slight shift of permittivity of maximum toward higher temperature with increasing frequencies.

By comparing the curves in Figure 1, we see that the broadness of dielectric response increases with an increase in $\mathrm{Zr} / \mathrm{Ti}$ ratio and the largest is at $\mathrm{Zr} / \mathrm{Ti}=49 / 51$. The temperature of dielectric permittivity maximum also increases with increase of $\mathrm{Zr} / \mathrm{Ti}$ ratio. All samples have a temperature called 

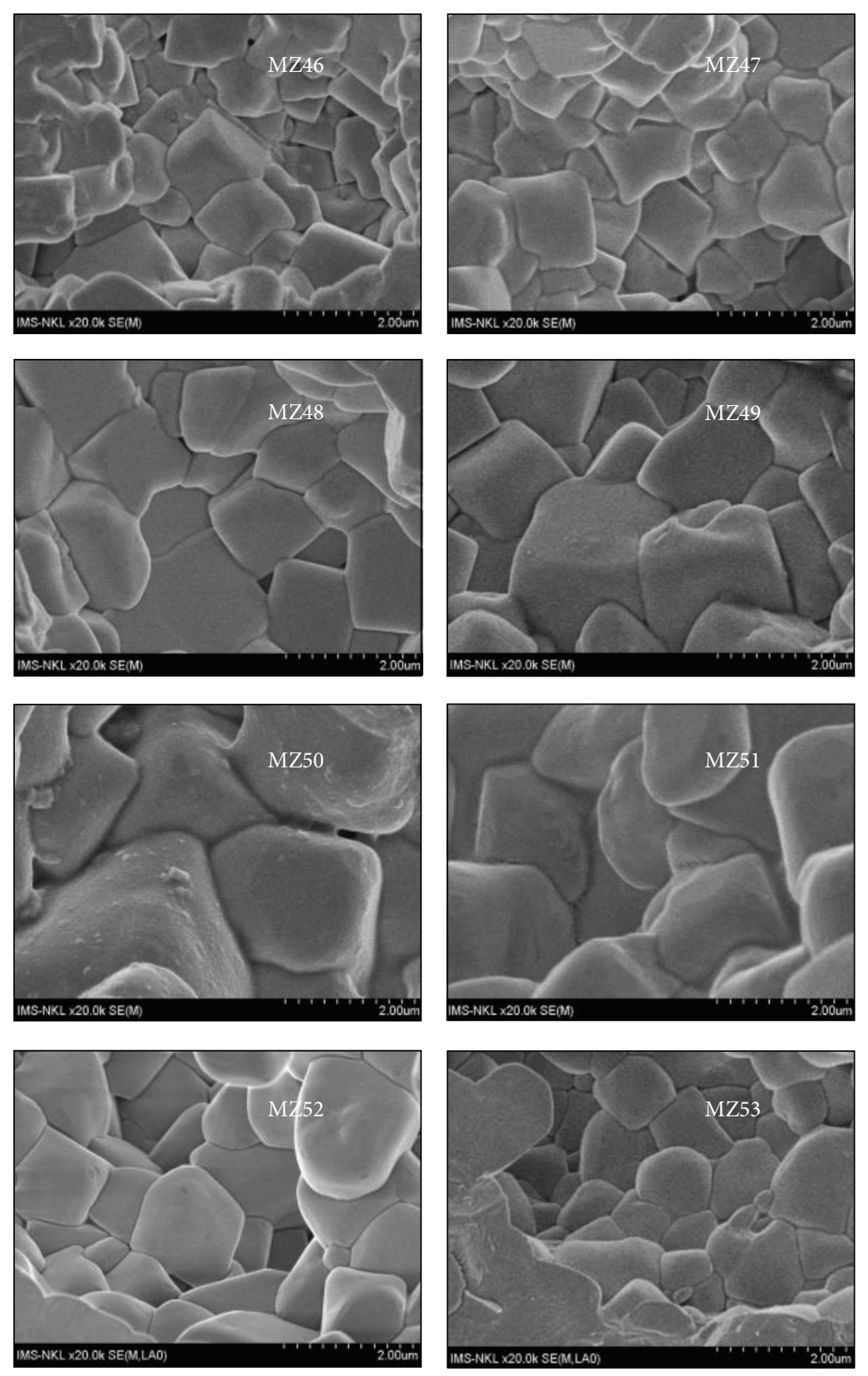

FIgURE 3: Surface morphologies observed by SEM of PZT-PMnN-PSN ceramics at various ratios of Zr/Ti.

Burn temperature at which dielectric response starts complying Curie-Weiss law and the system starts the transition into paraelectric phase.

Figure 5 shows Curie-Weiss dependence of the permittivity of the samples at temperatures start to $T_{B}$. The fitting parameters [14] are given in Table 1.

From Table 1, we can see that all the temperature values extend to decrease with the increase of $\mathrm{Zr} / \mathrm{Ti}$ ratio.

3.2.2. The Influence of $\mathrm{Zr} / \mathrm{Ti}$ Ratio on the Ferroelectric Properties. Figure 6 shows $P-E$ hysteresis loops of all samples. The well-saturated hysteresis loops were observed, and the values of remanent polarization $\left(P_{r}\right)$ and coercive field $\left(E_{c}\right)$ were presented in Table 2.

It's demonstrated that the hysteresis loops of all samples are of typical forms characterizing ferroelectric materials. The remanent polarization $\left(P_{r}\right)$ reaches the maximum value of $49.2 \mu \mathrm{C} / \mathrm{cm}^{2}$ and The coercive field $\left(E_{c}\right)$ reaches the minimum value of $10.28 \mathrm{kV} \cdot \mathrm{cm}^{-1}$ at $\mathrm{Zr} / \mathrm{Ti}=49 / 51$ (Figure 7).

\section{Piezoelectric Properties}

Figure 8 shows the piezoelectric and dielectric properties as a function of $\mathrm{Zr} / \mathrm{Ti}$ ratio. PZT-PMnN-PSN exhibits high 


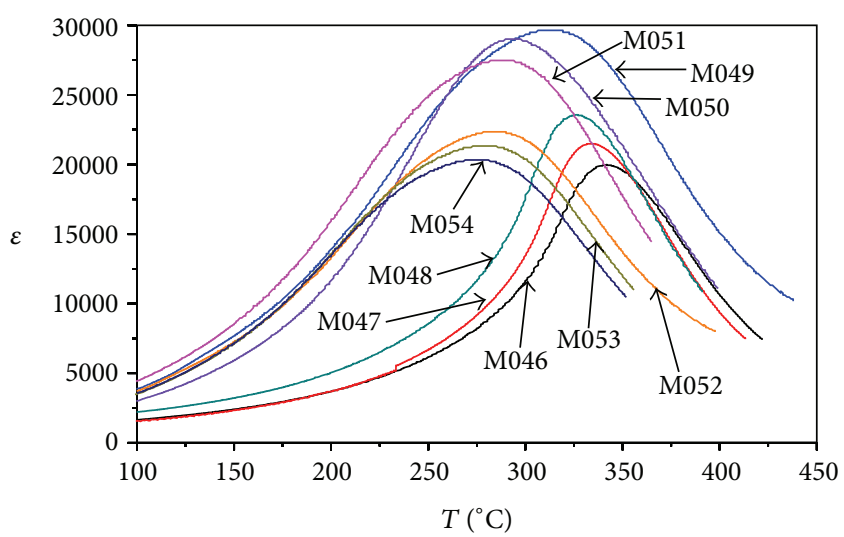

(a)

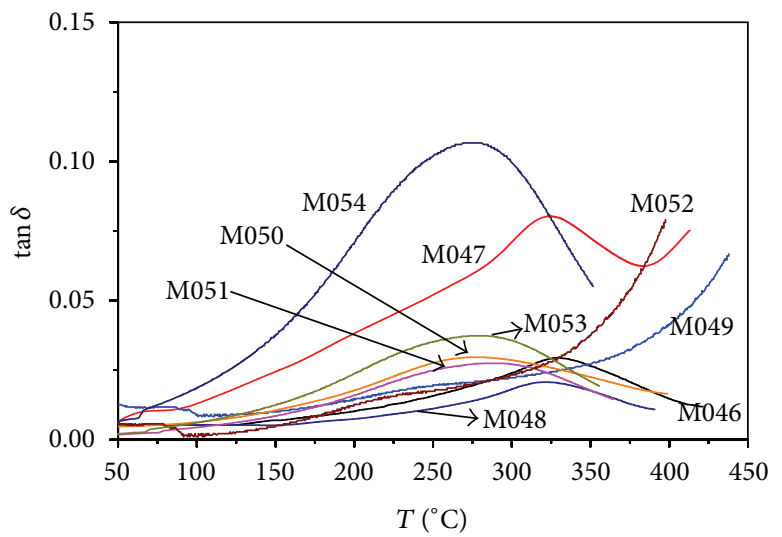

(b)

FIGURE 4: (a) Dielectric constant and (b) loss tangent of PZT-PMnN-PSN at various Zr/Ti ratios.

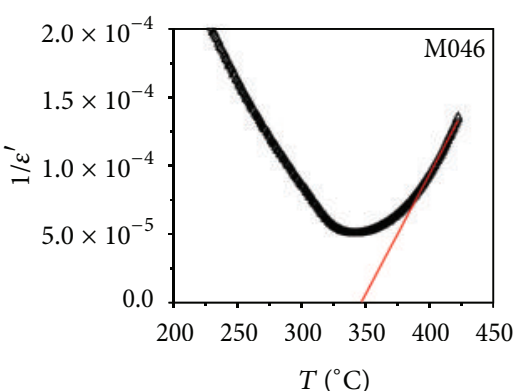

$\Delta \quad$ Experimental data

_ Fitting linear

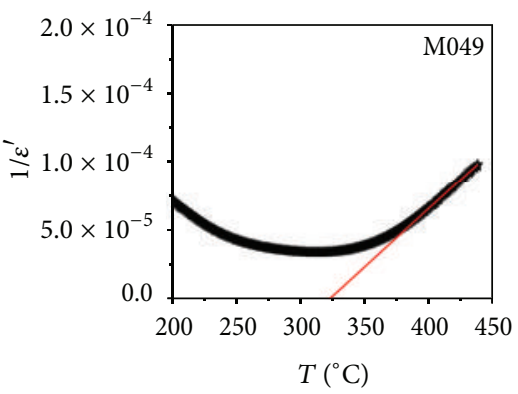

* Experimental data

_ Fitting linear

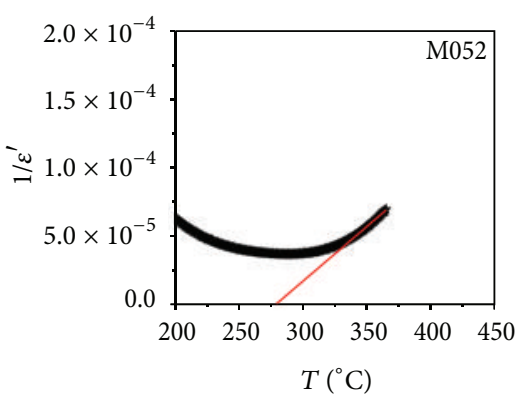

* Experimental data

— Fitting linear

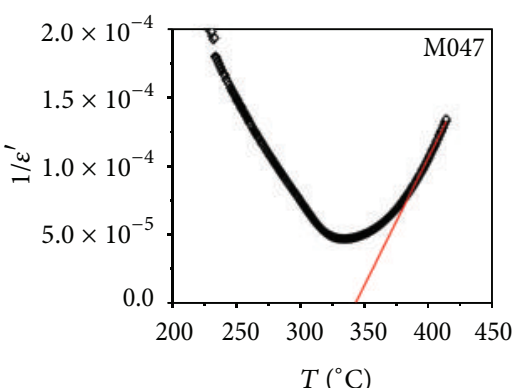

$\diamond \quad$ Experimental data

Fitting linear

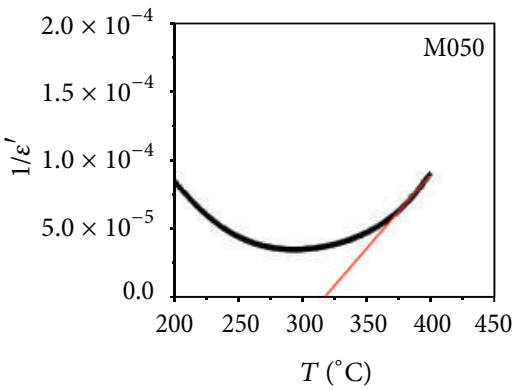

+ Experimental data

_ Fitting linear

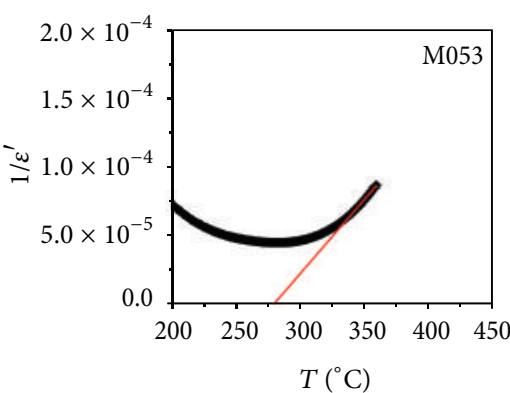

- Experimental data

— Fitting linear

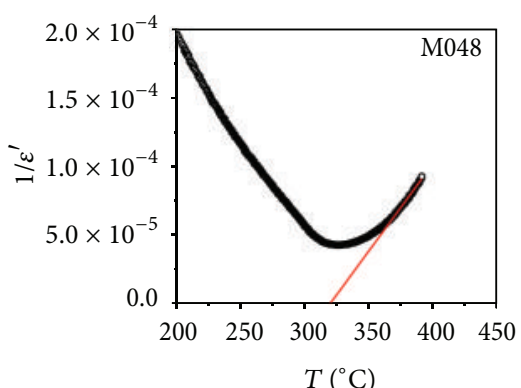

- Experimental data

_ Fitting linear

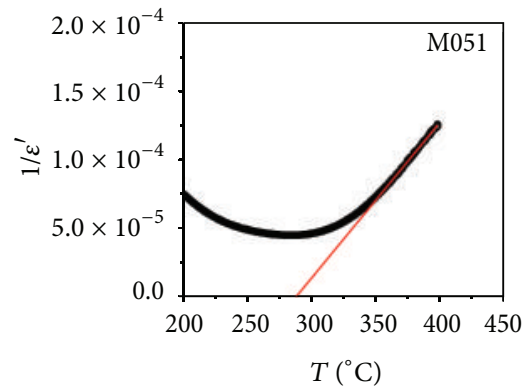

- Experimental data

_ Fitting linear

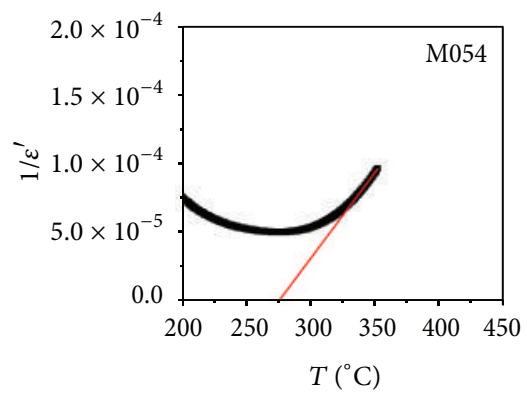

- Experimental data Fitting linear

FIGURE 5: Curie-Weiss dependence of the permittivity of the samples at temperatures start to $T_{B}$. 

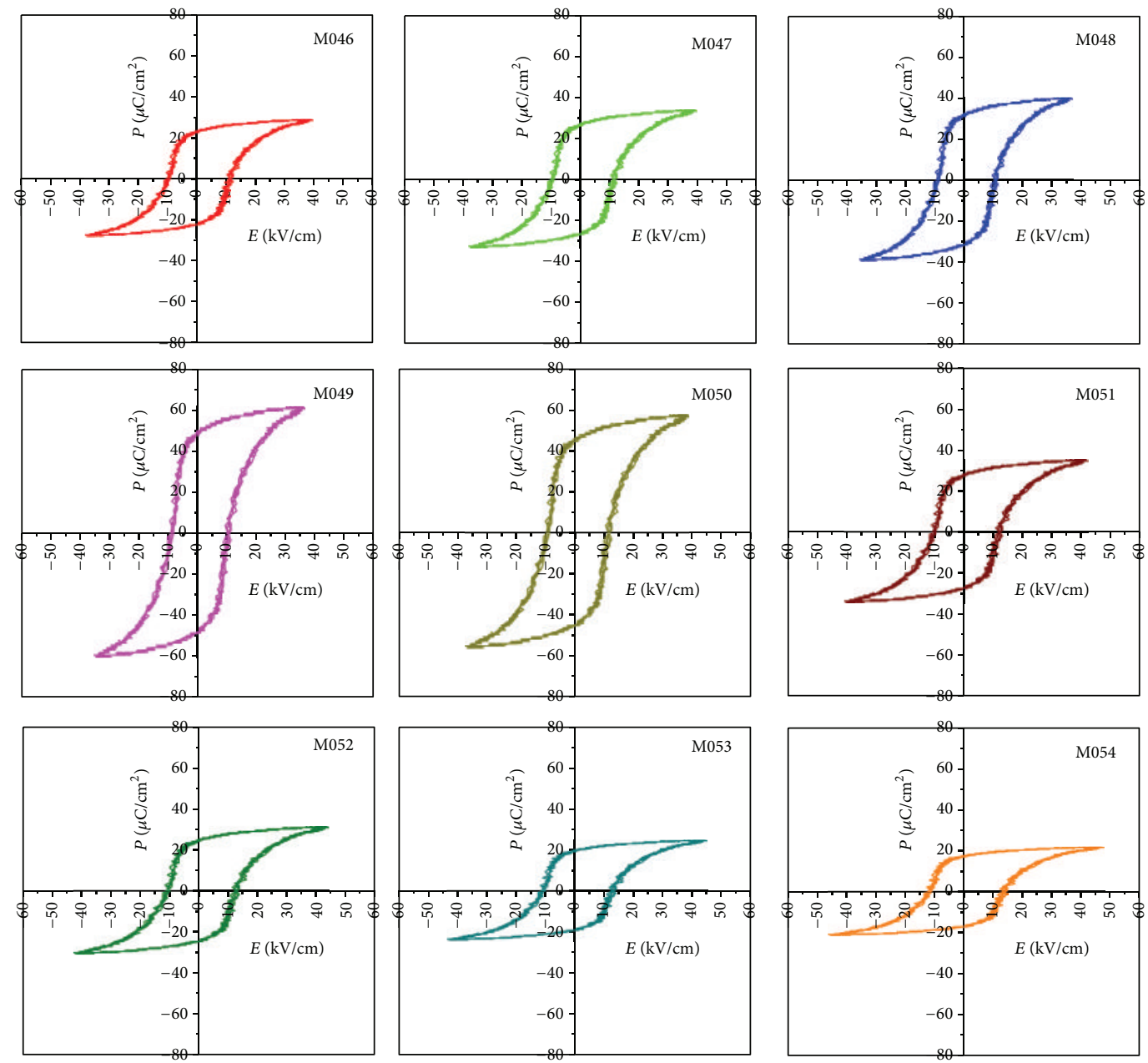

FIgURE 6: $P$-E hysteresis loops of PZT-PMnN-PSN samples.

TABLE 1: Dielectric properties and fitting parameters of PZT-PMnNPSN ceramics.

\begin{tabular}{lcccccc}
\hline Sample & $\varepsilon$ & $\tan \delta$ & $\varepsilon_{\max }^{\prime}$ & $\begin{array}{c}T_{m} \\
\left({ }^{\circ} \mathrm{C}\right)\end{array}$ & $\begin{array}{c}T_{B} \\
\left({ }^{\circ} \mathrm{C}\right)\end{array}$ & $\begin{array}{c}T_{C} \\
\left({ }^{\circ} \mathrm{C}\right)\end{array}$ \\
\hline M046 & 674 & 0.023 & 21343 & 343 & 390.3 & 347.4 \\
M047 & 699 & 0.035 & 21447 & 337 & 380.2 & 342.3 \\
M048 & 735 & 0.041 & 23050 & 325 & 375.8 & 330.8 \\
M049 & 899 & 0.044 & 29520 & 312 & 370.4 & 315.5 \\
M050 & 887 & 0.046 & 29018 & 298 & 366.9 & 304.6 \\
M051 & 756 & 0.022 & 27609 & 289 & 348.3 & 300.1 \\
M052 & 739 & 0.023 & 22348 & 280 & 342.5 & 292.4 \\
M053 & 692 & 0.014 & 21349 & 271 & 332.7 & 281.9 \\
M054 & 554 & 0.013 & 19875 & 266 & 325.3 & 274.4 \\
\hline
\end{tabular}

piezoelectric coefficient and electromechanical coupling factor around the MPB. From the trend of the variation of piezoelectricity, it reaches the maximum values of $d_{31}=$ $-236 \mathrm{pC} / \mathrm{N}, k_{p}=0.61$ at $\mathrm{Zr} / \mathrm{Ti}=49 / 51$.
TABLe 2: Calculated $P_{r}$ and $E_{c}$ values of samples.

\begin{tabular}{lcc}
\hline Sample & $E_{c}(\mathrm{kV} / \mathrm{cm})$ & $P_{r}\left(\mu \mathrm{C} / \mathrm{cm}^{2}\right)$ \\
\hline M046 & 11.32 & 23.0 \\
M047 & 11.07 & 27.0 \\
M048 & 10.37 & 32.0 \\
M049 & 10.28 & 49.2 \\
M050 & 10.88 & 46.0 \\
M051 & 11.85 & 28.0 \\
M052 & 12.40 & 25.0 \\
M053 & 12.66 & 19.7 \\
M054 & 13.45 & 17.3 \\
\hline
\end{tabular}

Simple diagram phase of PZT-PMnN-PSN ceramics near MPB, which is attractive system displaying excellent piezoelectric and dielectric properties, good electrostrictive effects, and relaxation of ferroelectric phase transition is shown in Figure 9. 


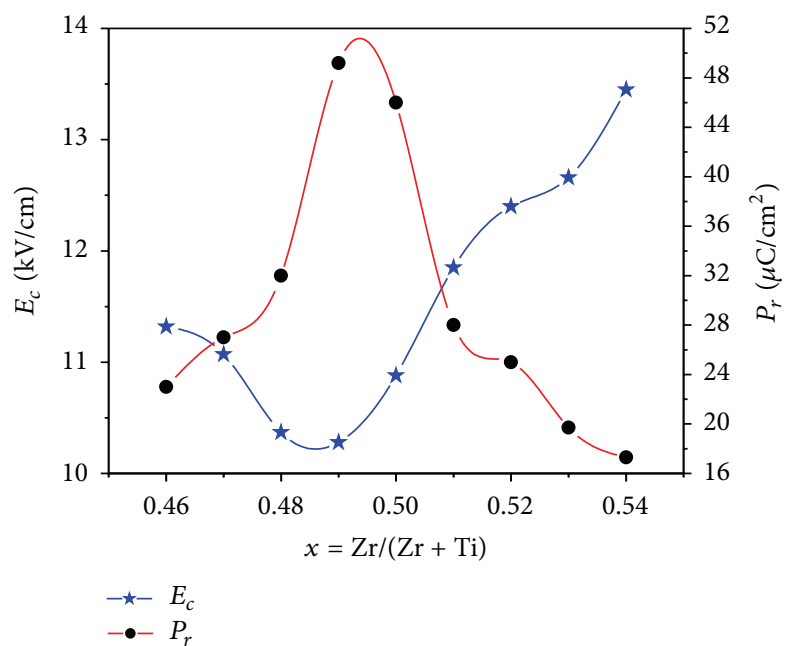

Figure 7: The $P_{r}$ and the $E_{c}$ as a function of $\mathrm{Zr}$ /Ti ratios.

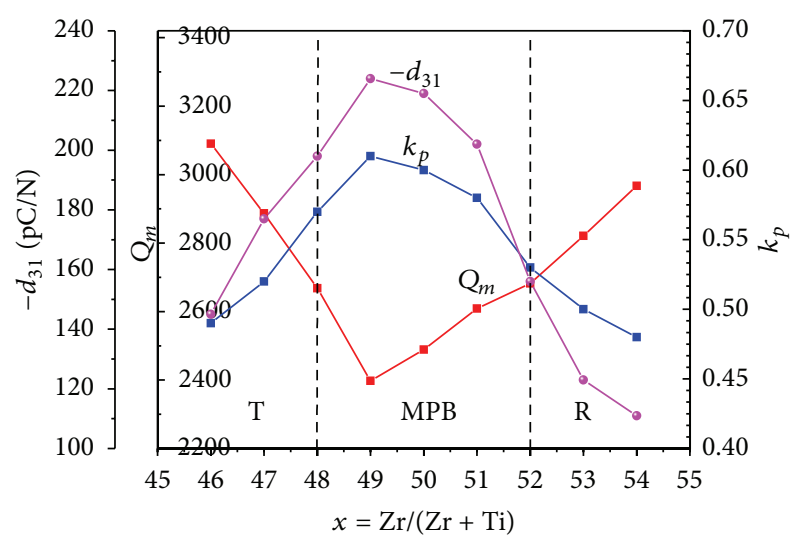

FIgURE 8: Piezoelectric properties of PZT-PMnN-PSN at various $\mathrm{Zr} / \mathrm{Ti}$ ratios.

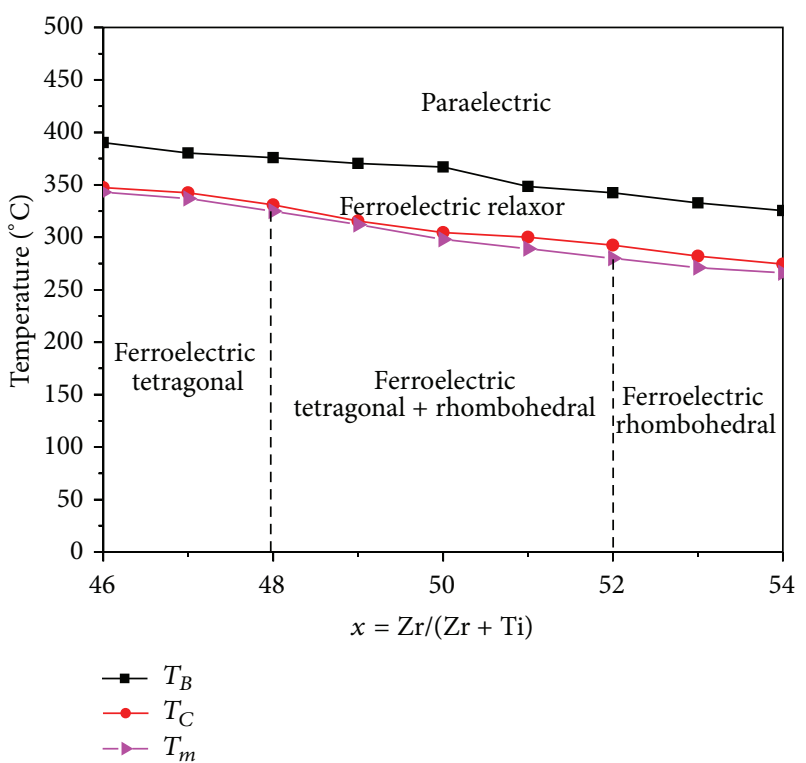

FIgURE 9: Simple diagram phase of PZT-PMnN-PSN system near MPB.

\section{Conclusion}

The results obtained from the experiment are as follows.

(1) PZT-PMnN-PSN ceramics with 7\% wt excess $\mathrm{PbO}$ were prepared by columbite method.

(2) The structure of ceramics sintered at $1150^{\circ} \mathrm{C}$ shows the pure perovskite structure in all ceramics specimens; the structure of PZT-PMnN-PSN ceramics was transformed from tetragonal to rhombohedra, with $\mathrm{Zr} / \mathrm{Ti}$ ratio increased in system.

(3) The composition of PZT-PMnN-PSN ceramics near the morphotropic phase boundary obtained is the ratio of $\mathrm{Zr} / \mathrm{Ti}=49 / 51$. At this ratio, the ceramic has the optimal electromechanical properties: the $k_{p}=0.61$, the $\varepsilon_{\max }=29520$, the $d_{31}=-236$ $\mathrm{pC} / \mathrm{N}$, the $Q_{m}=2400$, high remanent polarization $\left(P_{r}=49.2 \mu \mathrm{C} \cdot \mathrm{cm}^{-2}\right)$, and low coercive field $E_{c}=$ $10.28 \mathrm{kV} \cdot \mathrm{cm}^{-1}$.

(4) The piezoelectric ceramic with $\mathrm{Zr} / \mathrm{Ti}$ ratio of $49 / 51$ may be suitable for piezoelectric transformer applications and other high power devices.

\section{Conflict of Interests}

The authors declare that there is no conflict of interests regarding the publication of this paper.

\section{Acknowledgment}

This work is supported by the National Foundation for Science and Technology Development (NAFOSTED), no. 103.02.06.09.

\section{References}

[1] F. Gao, L. Cheng, R. Hong, J. Liu, C. Wang, and C. Tian, “Crystal structure and piezoelectric properties of $\mathrm{xPb}\left(\mathrm{Mn}_{1 / 3} \mathrm{Nb}_{2 / 3}\right) \mathrm{O}_{3}$ (0.2-x) $\mathrm{Pb}\left(\mathrm{Zn}_{1 / 3} \mathrm{Nb}_{2 / 3}\right) \mathrm{O}_{3}-0.8 \mathrm{~Pb}\left(\mathrm{Zr}_{0.52} \mathrm{Ti}_{0.48}\right) \mathrm{O}_{3}$ ceramics," Ceramics International, vol. 35, no. 5, pp. 1719-1723, 2009.

[2] Z. Necira, A. Boutarfaia, M. Abba, H. Menasra, and N. Abdessalem, "Effects of thermal conditions in the phase formation of undoped and doped $\mathrm{Pb}\left(\mathrm{Zr}_{1-\mathrm{x}} \mathrm{Ti}_{\mathrm{x}}\right) \mathrm{O}_{3}$ solid solutions," Materials Sciences and Applications, vol. 4, no. 5, pp. 319-323, 2013.

[3] Y. Xu, Ferroelctric Materials and Their Applications, NorthHolland, London, UK, 1991.

[4] J. Yoo, Y. Lee, K. Yoon et al., "Microstructural, electrical properties and temperature stability of resonant frequency in $\mathrm{Pb}\left(\mathrm{Ni}_{1 / 2} \mathrm{~W}_{1 / 2}\right) \mathrm{O}_{3}-\mathrm{Pb}\left(\mathrm{Mn}_{1 / 3} \mathrm{Nb}_{2 / 3}\right) \mathrm{O}_{3}-\mathrm{Pb}(\mathrm{Zr}, \mathrm{Ti}) \mathrm{O}_{3}$ ceramics for high-power piezoelectric transformer," Japanese Journal of Applied Physics A, vol. 40, no. 5, pp. 3256-3259, 2001.

[5] R. Muanghlua, S. Niemchareon, W. C. Vittayakorn, and N. Vittayakorn, "Effects of $\mathrm{Zr} / \mathrm{Ti}$ ratio on the structure and ferroelectric properties in PZT-PZN-PMN ceramics near the morphotropic phase boundary," Advanced Materials Research, vol. 55-57, pp. 125-128, 2008.

[6] F. Kahoul, L. Hamzioui, N. Abdessalem, and A. Boutarfaia, "Synthesis and piezoelectric properties of $\mathrm{Pb}_{0.98} \mathrm{Sm}_{0.02}$ 
$\left[\left(\mathrm{Zr}_{\mathrm{y}}, \mathrm{Ti}_{1-\mathrm{y}}\right)_{0.98}\left(\mathrm{Fe}_{1 / 2}^{3+}, \mathrm{Nb}_{1 / 2}^{5+}\right)_{0.02}\right] \mathrm{O}_{3}$ ceramics," Materials Sciences and Applications, vol. 3, pp. 50-58, 2012.

[7] N. D. T. Luan, L. D. Vuong, and B. C. Chanh, "Microstructure, ferroelectric and piezoelectric properties of PZT-PMnSbN ceramics," International Journal of Materials and Chemistry, vol. 3, pp. 51-58, 2013.

[8] M. Kobune, Y. Tomoyoshi, A. Mineshige, and S. Fujii, "Effects of $\mathrm{MnO}_{2}$ addition on piezoelectric and ferroelectric properties of $\mathrm{PbNi}_{1 / 3} \mathrm{Nb}_{2 / 3} \mathrm{O}_{3}-\mathrm{PbTiO}_{3}-\mathrm{PbZrO}_{3}$ ceramics," Journal of the Ceramic Society of Japan, vol. 108, no. 7, pp. 633-637, 2000.

[9] S. J. Yoon, A. Joshi, and K. Uchino, "Effect of additives on the electromechanical properties of $\mathrm{Pb}(\mathrm{Zr}, \mathrm{Ti}) \mathrm{O}_{3}-\mathrm{Pb}\left(\mathrm{Y}_{2 / 3} \mathrm{~W}_{1 / 3}\right) \mathrm{O}_{3}$ ceramics," Journal of the American Ceramic Society, vol. 80, no. 4, pp. 1035-1039, 1997.

[10] Y. K. Gao, Y. H. Chen, J. H. Ryu, K. J. Uchino, and D. Viehland, "Eu and $\mathrm{Yb}$ substituent effects on the properties of $\mathrm{Pb}\left(\mathrm{ZrM}_{0.52} \mathrm{Ti}_{0.48}\right) \mathrm{O}_{3}-\mathrm{Pb}\left(\mathrm{Mn}_{1 / 3} \mathrm{Sb}_{2 / 3}\right) \mathrm{O}_{3}$ ceramics: development of a new high-power piezoelectric with enhanced vibrational velocity," Japanese Journal of Applied Physics, vol. 40, no. 2, pp. 687-693, 2001.

[11] Z. L. Gui, L. T. Li, H. Q. Lin, and X. W. Zhang, "Low temperature sintering of lead magnesium nickel niobate zirconate titanate (PMN-PNN-PZT) piezoelectric ceramic, with high performances," Ferroelectrics, vol. 101, no. 1, pp. 93-99, 1990.

[12] Z. Yang, H. Li, X. Zong, and Y. Chang, "Structure and electrical properties of PZT-PMS-PZN piezoelectric ceramics," Journal of the European Ceramic Society, vol. 26, no. 15, pp. 3197-3202, 2006.

[13] H. Fan and H. Kim, "Perovskite stabilization and electromechanical properties of polycrystalline lead zinc niobate-lead zirconate titanate," Journal of Applied Physics, vol. 91, no. 1, pp. 317-322, 2002.

[14] A. Quintana-Nedelcos, A. Fundora, H. Amorín, and J. M. Siqueiros, "Effects of $\mathrm{Mg}$ addition on phase transition and dielectric properties of $\mathrm{Ba}\left(\mathrm{Zr}_{0.05} \mathrm{Ti}_{0.95}\right) \mathrm{O}_{3}$ system," The Open Condensed Matter Physics Journal, vol. 2, pp. 1-8, 2009.

[15] L. D. Vuong, P. D. Gio, T. Van Chuong, D. T. H. Trang, D. V. Hung, and N. T. Duong, "Effect of Zr/Ti ratio content on some physical properties of the low temperature sintering PZTPZN-PMnN ceramics," International Journal of Materials and Chemistry, vol. 3, no. 2, pp. 39-43, 2013. 

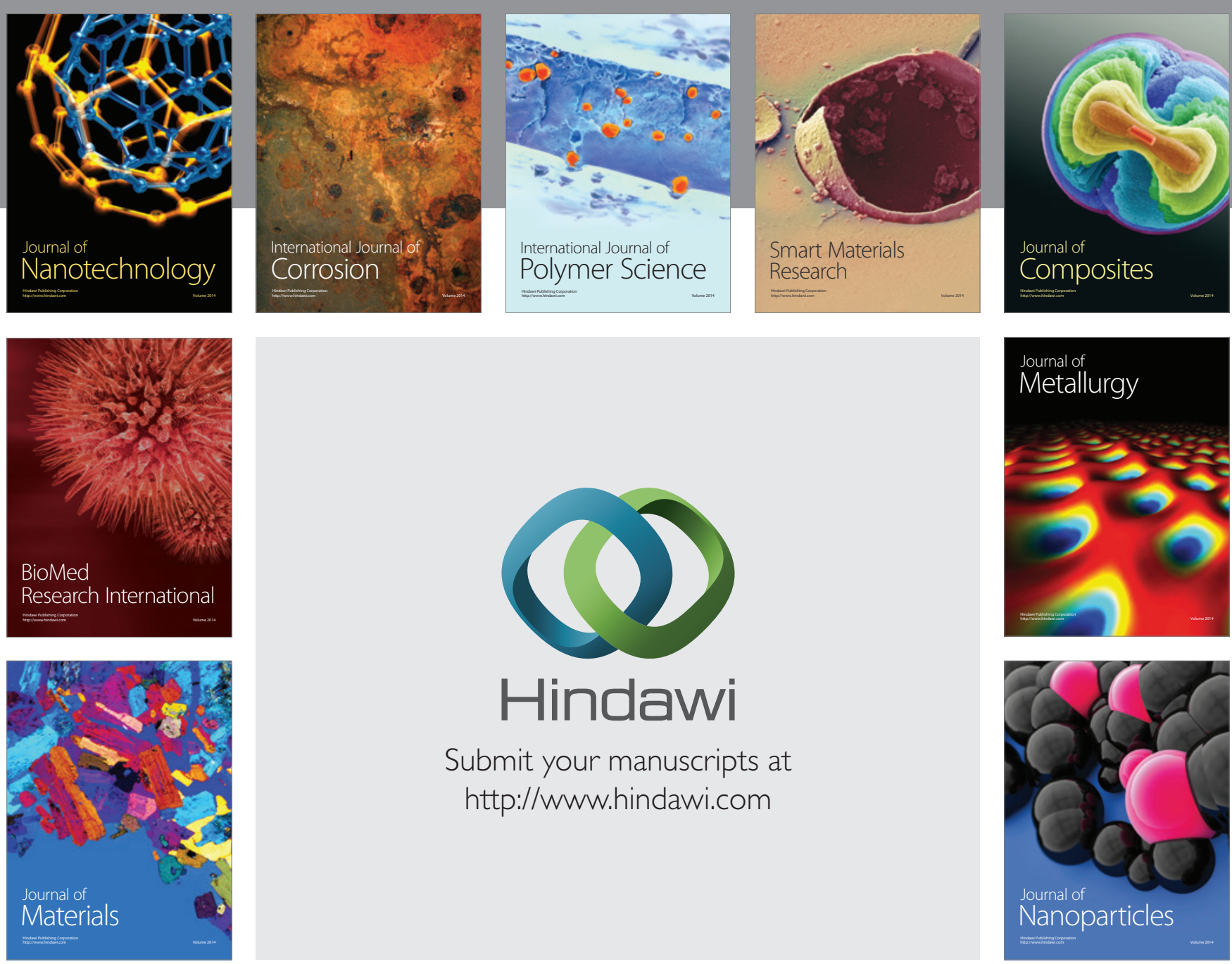

Submit your manuscripts at http://www.hindawi.com
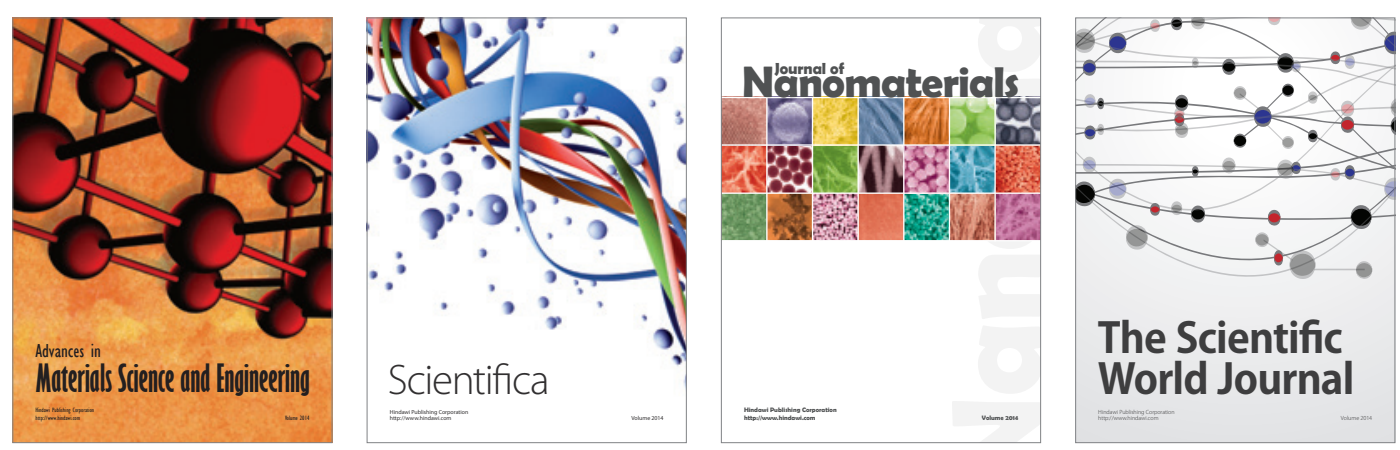

\section{The Scientific World Journal}
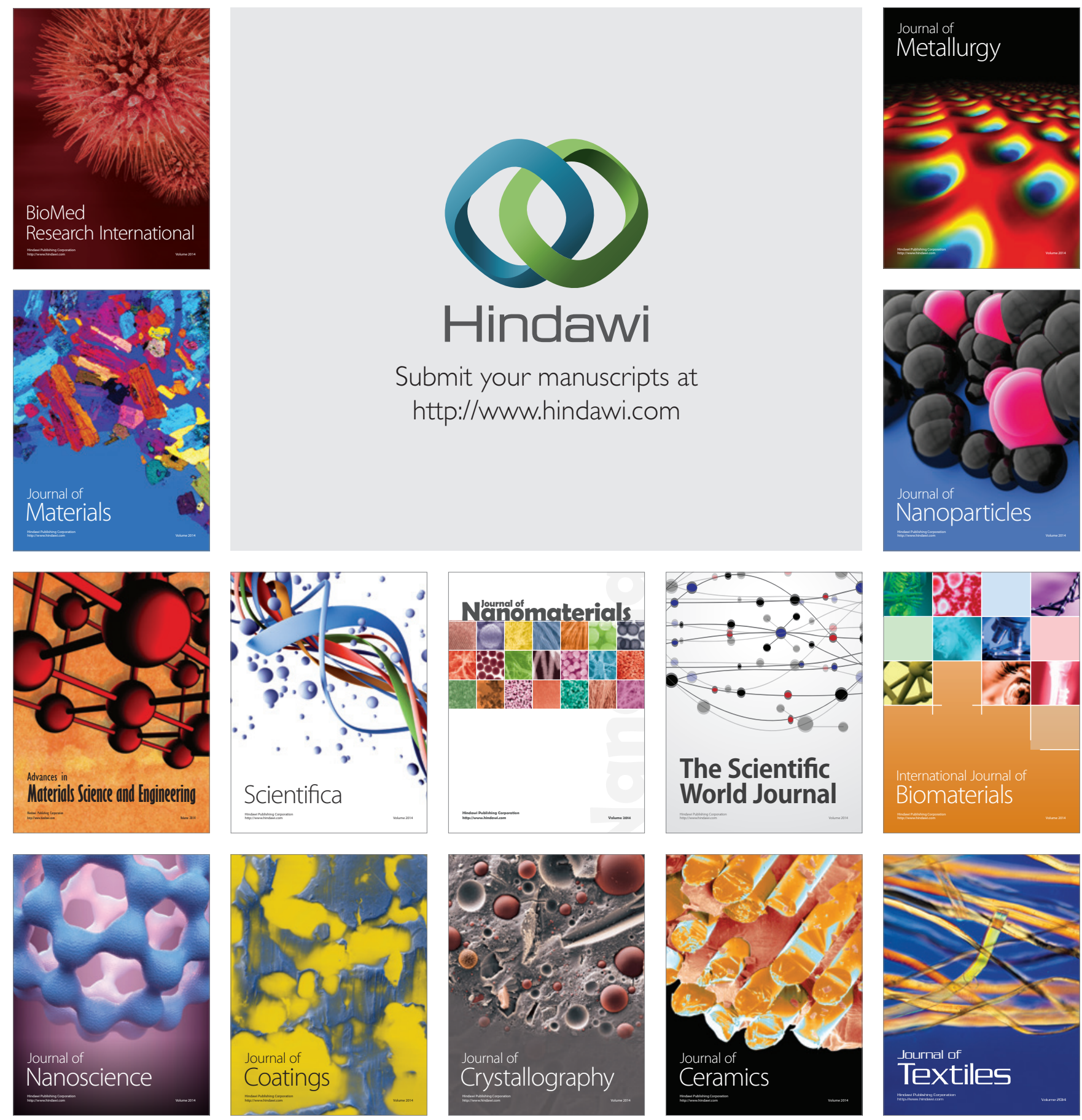